\title{
Development ethics: talking to recipients of development funds about vulnerability and human dignity
}

\author{
John Mary Mooka Kamweri ${ }^{1}$
}

Published online: 24 May 2016

(C) Springer International Publishing AG 2016

\begin{abstract}
The often deplorable stories of corruption, lack of transparency and accountability, raises concern that the ethical foundation for the global development initiative is yet to resonate with some recipients of development funds in Uganda and elsewhere. Ethicists consider the notion of social justice as the appropriate category for articulating the moral demands of promoting development in resource-poor countries. The social justice approach entails acknowledgement of the inviolable dignity and inherent value of a human person. The language of vulnerability is often used in reference to the need to provide those in less developed countries with adequate support for socio-economic development, so as to enhance individual freedoms and dignity. This endeavor draws support from the Universal Declaration of Human Rights that regards the principle of human dignity as foundational for freedom, peace, and justice in the human family. However there is no clear mechanism for relaying this moral discourse to recipients of development funds in rural communities in Uganda. Too often this gap is filled in by human rights activist who are at times prone to human rights reductionism. To maintain high ethical standards a new approach necessitates the articulation of a set of UNESCO's bioethics principles that include human dignity, respect for human vulnerability and personal integrity, solidarity and cooperation, autonomy and individual responsibility. This presentation demonstrates a strategy of using workshops in rural communities to specify and analyze the substantive and procedure issues involved in the ethical principles that are relevant to socio-economic development.
\end{abstract}

Keywords Developmentethics $\cdot$ Development funds $\cdot$ Donors $\cdot$ Resipients ofdonor funds - Social justice $\cdot$ Rural communities $\cdot$ Bioethics principles $\cdot$ Human dignity $\cdot$ Vulnerability

Paper Presented at $2^{\text {nd }}$ International Conference on Ethics Education (IAEE) 2014 Congress, $21^{\text {st }}$ to $23^{\text {rd }}$ of May 2014 in Ankara.

John Mary Mooka Kamweri

bbbuganda@gmail.com

1 Uganda Martyrs University, Kampala, Uganda 


\section{Ethical obligations to donors}

Two ethical notions of transparency and accountability often top the agenda in workshops organized by Community-Based Organizations (CBOs), in rural communities in Uganda, to discuss the ethical obligations recipients of donor funds have towards donors. In a development model that prioritizes wealth creation and distribution of economic opportunities, and when the focus is on quantitative goal achievements, transparency and accountability provide an appropriate framework for the ethical discourse. The aim here is to establish whether the funds allocated to recipients have been spent, exhausted, and utilized to meet the targeted objectives. The focus is more on the funds and utilization, and less on discovering the essential features of humanness that underlie the donor's development act and how that act enhances the human quality of life.

For instance, discussions based on transparence and accountability used to dominate workshop proceedings organized by a Catholic Nun in Jinja, Uganda, to educate members of a small community-based organization on how to best relate to donors. Collaborative Hands of Love in Family Outreach (CHLFO) is a CBO consisting of 130 families of widows, widowers and women living with HIV/AIDS from five villages, who through a small savings and loans scheme endeavor to improve their livelihoods. They engage in small income generating activities such as vegetable growing, tailoring, knitting, wine-making, among others. Although CHLFO members were meant to relate to each other in a spirit of "collaborative hands of love," Sr. Vilgo was getting frustrated that selfishness was stunting development and endangering donor confidence in the development project. Two workshops were organized in 2013 and 2014 to shift the focus from quantitative goals achievement to the appreciation of the spirit of humanness and relatedness that underlie the donor act. CHLFO is a better loving community now and with moderate gains in quality of lives - although still with meager funding.

\section{Didactic factor}

Workshop participants were given an opportunity to discuss the underlying aims of donor - recipient collaboration in development programs. Most participants focused on quantitative goals such as availability of funds, attainment of skills, and increased income. The quantifiable elements of the discussion were identified and classified under the factors of: input, activities, output, and outcome Table 1.

When discussing impact, participants focused on the individual's external gains and barely made reference to interpersonal relationships, group dynamics, and inner human transformation as a result of the donor-funding act. Discussion of the notions of accountability and transparence featured mainly in connection with complying with the donors' demand for procedural elements of the collaboration. The essential features of group dynamics such as collaboration, cooperation, communication, and coordination were seen more in terms of instrument values to enable the individuals achieve their personal quantitative goals, rather than essential features of humanness and in respect to improving the quality of the lives of other.

To enable participants appreciate more fully the donors' act as a promotion and defense of the homogeneity of humanness, participants were engaged in a discussion on foundational issues in the ethics of development. This involved discussion of the 


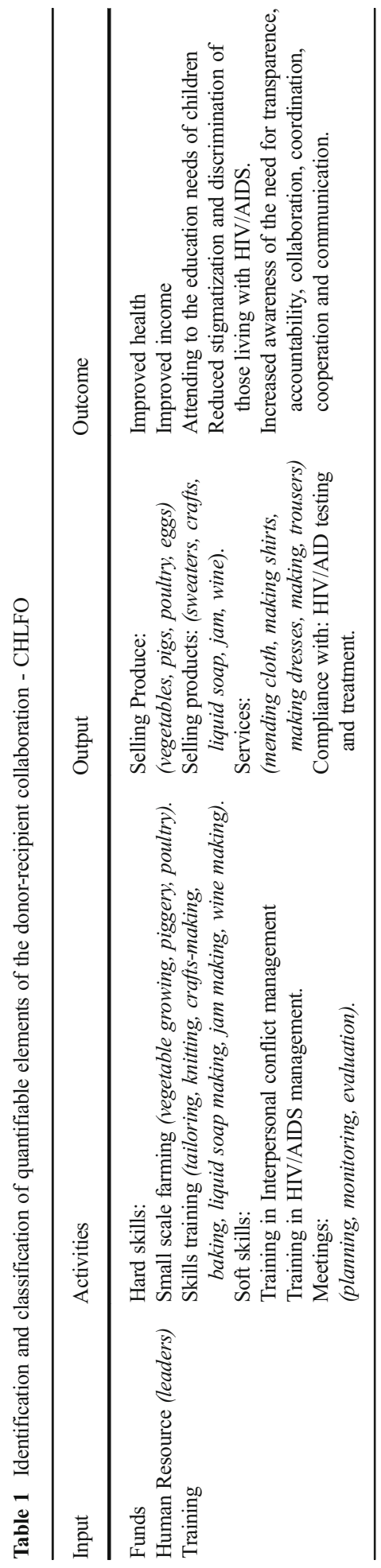


notions of sustainable development and social justice, and the use of ethical principles to harness the moral terminal values of the donor-recipient act. Emphasis was put on the ethical principles prioritized in the UNESCO Universal Declaration on Bioethics and Human Rights (UDBHR). Of specific importance were the principles of human dignity, respect for human vulnerability and personal integrity, autonomy and individual responsibility, and, solidarity and cooperation.

It was important to clarify to participants that these ethical principles are presented as normative standard setting that cut across cultural diversity and allows for plurality of viewpoints (ten Have and Jean, 2009, pp.31-32). Only ethical principles most relevant to resolving the ethical problems identified in the CHLFO workshop were selected out of the fifteen UDBHR principles. It is not the hierarchical order of the ethical principles that is important, but the weight of the ethical principle (fundamental, derived, or procedural) in relation to the nature of the ethical problem in development that is to be engaged.

\section{Discussion - development as a social justice issue}

Beginning in the 1990, a shift begun to occur globally in the understanding of what development is. Rather than emphasizing development as meaning (economic) growth (increases of gross national productivity), and as market oriented (to maximize output), critics introduced the notion of sustainable development to provide for environmental protection. But even with this framework, determinants of substantive human freedom were absent from what was to be sustained (Donnelly, 2003, pp.194-5). This argument is succinctly framed by Amartya Sen that development also entails the removal of unfreedoms such as poverty, tyranny, social deprivation, intolerance, and repression by states (Sen 1999). The perspective of human freedoms led to the understanding of human development as social justice issue (Donnelly, 2003, 195).

Donnelly (2003) points out that this approach is articulated in the United Nations Development Plan's vision of sustainable human development. UNDP outlined five aspects of sustainable development to impact on the lives of the vulnerable and the poor in a manner that expands the choices of all people in society. The five aspects are: empowerment, cooperation, equity, sustainability, and security. But critics are also quick to point out that such a definition leaves unaddressed the connection of human rights to economic development, which is an "important domain of contemporary social action and aspiration."

Ethicists now point to the heterogeneous nature of development and demand a new approach that is anchored in a robust human rights framework. Development is understood as "a matter of promoting the capabilities of people in order to enhance their freedom and choice rather than merely improving their income (George 2008, p.22)." This new perspective in development ethics, as George (2008) states, also means that economics is understood as "a humanistic inquiry rather than the dismal science of wealth (p.30)." What links the donor to the recipient of donor funds is the homogeneity of humanness and the need to empower one another and society.

This discourse started with the paradigm shift Amartya Sen brought to development ethics when he argued that development should not ultimately be seen in terms of economic growth or modernization, but as a means of expanding people's valuable 
capabilities and functionings (Sen 1999). In this sense development occurs within the enabling context of freedom. Taking the term "capability approach" to be synonymous with "human development approach", Nussbaum (2008) concurred with Sen, and with MahbubUlHuq views that the "purpose of development is to create an enabling environment for people to enjoy long life, health, and creative lives (p.111)." By linking the goals of development to equality, health, education, and other social goals, Sen and colleagues understood development in terms of social justice (Nussbaum 2008, p.113).

From this perspective, the notion of social justice has emerged as an appropriate category for articulating the ethical demands of promoting development. The social justice approach entails the acknowledgement of the inviolable dignity and inherent worth of a human person. This view draws support from the Universal Declaration of Human Rights (1948) that regards the principles of respect for human dignity and respect for human vulnerability and personal integrity as foundational for freedom, peace, and justice in the human family (ten Have and Jean, 2009, p.91). Subsequently, the language of human rights is deployed to make practical the demands of social justice. In this sense, human rights are defined as "a principle of justification with respect to what is due each person and which each person must dutifully respect in others, in virtue of being a human being (Rosenbaum 1980, p.25)."

In global ethics, dignity refers to "a distinct characteristic in a person," and to the "recognition of the intrinsic (inalienable) value in each person's humanity" (Haugen 2010, p.207). Connectedly, freedom means "the ability to make choices and accept responsibility arising from the choices made" (George 2008, p.22). Subsequently, the goal of development work is to make the subject free - independent, responsible, and with the capability to make further development happen (George 2008, pp.20-1). However, while those committed to rights advocacy in Uganda are well drilled in articulating entitlements of rights-holders and obligations of duty-bearers, they are not often good at delineating the nature and practice of reciprocal ethical obligations of donors and recipients of development funds that arise from the notions of dignity, vulnerability and integrity.

The principles of human dignity, vulnerability, and integrity are interlinked; and, are central to the goals of development work. However this connection has not often been adequately relayed to recipients of donor-funds. Familiarity with the principles-based framework, as suggested in the UNESCO's Universal Declaration on Bioethics and Human Rights, can bring improvement to the way development ethics education is passed on to beneficiaries of donor funds in community-based organizations. But as aforementioned this will require the use and mastery of a double strategy of classification of principles as: fundamental principles, derived principles and procedural principles; and the specification of principles. This will enable the grounding of ethical issues, in development work, in a robust and coherent universal principles ethical framework.

\section{Use of ethical principles}

I have found it useful, when applying the principles framework to consider two complementary strategies of: (i) classifying principles; and (ii) specifying principles. The International Bioethics Committee (IBC) of UNECSO provided guidance on classifying principles as: fundamental principles, derived principles, and procedural 
principles (or standards). Accordingly, fundamental principles were defined as "basic principles that cannot be justified by any other principle" or "derogated". Derived principles are those principles that "can only be justified by one or more fundamental principles." Procedural principles "describe the rules to follow and the framework to be put in place for the application of the principles, especially when a balance needs to be found between the application of several principles that seem relevant at the same time" (ten Have and Jean, 2009, pp.31-32). For instance, human dignity is a fundamental principle. It cannot be justified by any other principle. Freedom and equality are derived principles from human dignity. But freedom and equality can also be justified on the basis of another fundamental principle of integrity.

Principles do not always have the same weight and importance in a given situation; by identifying fundamental principles, derived principles and procedural principles, we acknowledge the need to anchor specific ethical concerns around robust and coherent values. Coherence here refers to the harmony between terminal values (goals), procedural values (process), and substantive values (criteria). This distinction has enormous implication when understood in relation to Beauchamp and Childress' exposition on specification (the operationalization of principles) and balancing of principles. A basic principle, such as autonomy, can be specified to mean many things, such as, informed consent, self-governance, privacy, and confidentiality (Beauchamp and Childress, 2001). Informed consent in this sense is a derived principle from autonomy. This derived principle can further be specified to imply procedural issues such as information, understanding and voluntariness.

When talking to recipients of development funds about the principles of respect for human dignity and respect for human vulnerability and integrity, both strategies of classification and specification of principles are important. Once inherent dignity has been classified as a fundamental principle, we draw from it, by specification, the derived principles of equality, freedom, liberty, justice and peace. The principles are derived in the context of the Universal Declaration of Human Rights (1948) which stipulates that "all human beings are born free and equal in dignity and rights (article 1). The Declaration affirms the inherent dignity of all members of the human family and credits inherent dignity as the foundation for freedom, justice and peace (preamble). According to Andorno (2009), even in the absence of a concise definition of the term "human dignity" we cannot lose focus of the reality that dignity "reflects a real concern about the need to ensure respect for the inherent value of every human being and of humanity (p.93)."

Sen, in his work Development as Freedom (1999) effectively demonstrated the operationalization (specification) of the (derived) principle of freedom in development work. For Sen, development is synonymous with means to expanding the freedom enjoyed by the members of society. These freedoms are: political freedom, economic freedom, social opportunities (health, education, and other social services), transparency guarantees, and protective security (Sen 1999). Providing more clarity to the notion of development as freedom, Sen draws to attention the need to expand the capabilities of persons "to lead the kind of lives they value - and have reason to value (Sen 1999, p.18)." This notion of capabilities is linked to the principle of respect for human vulnerability and personal integrity.

The common understanding of vulnerability is in reference to conditions of decreased capabilities and reduced personal autonomy. These conditions may result from internal factors of the person, such as illness and disability. Vulnerability could also 
result from external factors such as lack of education, land, and unfair distribution of gender-based roles. Other sources could be specific conditions such as interpersonal relationships. Factors such as poverty and poor health are understood as causing low levels of capabilities. Gender-based roles that result in unequal access to family resources, as distributed by some cultural institutions, result in the diminution of the exercise of individual autonomy. From this perspective, development is understood in terms of increased capabilities to enhance freedoms and human wellbeing rather than solely welfare and creation of wealth (George 2008, p.20). Accordingly, selfdetermination and respect for the dignity of individual persons are regarded as essential dimensions of human wellbeing (Power and Fadden 2006, pp.18-2).

Vulnerability as understood by bioethicists and as argued in the UNESCO Universal Declaration on Bioethics and Human Rights, encompasses two meanings. The first is vulnerability as a universal principle, and as understood in Continental European tradition, entailing a basic "human condition, inherent to existence in its radical finitude and fragility", and that which cannot be eliminated. Accordingly, vulnerability requires the "care of others, the responsibility and solidarity of others in the recognition and non-exploitation of that condition (Neves 2009, pp.156-7)." The second definition of vulnerability entails substantive incapacity to protect ones interests and is in reference to classes or categories of individuals, subjects, persons, groups, populations deserving special protection (Haugen 2010, p.209; Neves 2009, 156-7).

Having elucidated on the use of UNECO's Bioethics principles approach to create harmony between development goals, process and criteria, attention was turned to a local ethical instrument in Uganda. Ten (Core) National Ethical Values were identified by the Directorate for Ethics and Integrity (DEI), Office of the President, as setting the ethics framework to guide ethical conduct of Ugandans. On the list, the second ethical value is "honesty." Accordingly, honesty means to "harness a character of truthfulness and conducting oneself in an open manner and willing to give satisfactory explanation for actions and acts of omission or commission; demonstrating right judgment and make objective decisions; be truthful and sincere at all times in pursuit of personal and national aspiration" (DEI 2013).

This definition was understood as implying notions such as transparency and accountability, among others. In this sense, transparence and accountability are not understood as the terminal values, but as procedural. Underlying those procedural values are the derived ethical principles of truthfulness, sincerity, openness, and objectivity. In this case, they are derived from the ethical principle of honesty. Honesty is an essential feature of humanness, which underlie the donor's development act whose terminal goal is enhancing the human quality of life.

\section{Conclusion}

The classification and specification methods of elucidating and applying ethical principles was used in the two development workshops to enable members of the Jinja community-based organization, CHLFO, to understand their relationship with donors' as an act of humanness. Human dignity, vulnerability, honesty and integrity, are essential feature of humanness, which underlie the donor's development act whose terminal goal is enhancing the human quality of life. 


\section{References}

Andorno, Roberto. 2009. Article 3: Human dignity and human rights. In The UNESCO universal declaration on bioethics and human rights: Background principles and application, ed. Henk ten Have and Michele Jean. Paris: UNESCO Publishing.

Beauchamp, Tom, and James Childress. 2001. Principles of biomedical ethics, 5th Edition. New York, NY: Oxford University Press.

Directorate for Ethics and Integrity - Office of the President. 2013. The national ethical values policy. Kampala: The Government of Uganda.

Donnelly, Jack. 2003. Universal human rights in theory and practice, 2nd Edition. Ithaca and London: Cornell University Press.

George, Siby. 2008. Birth of the subject: The ethics of monitoring development programmes. Journal of Global Ethics 4(1): 19-30.

Haugen, Hans Mortem. 2010. Inclusive and relevant language: The use of the concept of autonomy, dignity and vulnerability in different contexts. Medical, Health Care and Philosophy, A European Journal 3(3): 203-213.

Neves, Maria P. 2009. Article 8: Respect for human vulnerability and personal integrity. In The UNESCO universal declaration on bioethics and human rights: Background principles and application, ed. Henk ten Have and Michele Jean. Paris: UNESCO Publishing.

Nussbaum, Martha C. 2008. Constitutions and capabilities. In Democracy in a global world: Human rights and political participation in the $21^{\text {st }}$ century, ed. Deen K. Chatterjee. UK: Rowman\& Littlefield Publishers, Inc.

Power, Madison, and Ruth Fadden. 2006. Social justice: The moral foundation of public health and health policy. New York: Oxford University Press.

Rosenbaum, Alan (ed.). 1980. The philosophy of human rights: Interpretation perspectives. Westport: Greenwood Press.

ten Have, Henk AMJ, and Michele Jean (eds.). 2009. The UNESCO universal declaration on bioethics and human rights: Background principles and application. Paris: UNESCO Publishing.

Sen, Amartya. 1999. Development as freedom. New York: Anchor Books. 